\title{
Agudização da barbárie e desafios ao Serviço Social*
}

\section{Intensification of barbarism and challenges to Social Work}

\author{
Ivanete Boschetti \\ Professora do Departamento de Serviço Social e do Programa de Pós-Graduação em Política \\ Social da UnB/Brasília, Brasil; doutora e pós-doutora em Sociologia pela EHESS/Paris.
}

ivanete@unb.br

\begin{abstract}
Resumo: A crise estrutural do capital agudiza as expressões da questão social e revela a barbárie cotidiana que assola sem trégua a classe trabalhadora. Avolumam-se as demandas ao Serviço Social, sobretudo em decorrência da supressão dos direitos e do processo de pauperização em contexto de avanço acelerado do reacionarismo e do conservadorismo no Brasil. Velhos e novos desafios reafirmam a pertinência do Projeto Ético-Político profissional.
\end{abstract}

Palavras-chave: Crise do capital. Barbárie. Serviço Social.

\begin{abstract}
The structural crisis of capital intensifies the expressions of the social issue, and it reveals the daily barbarism that ravages the working class restlessly. The demands on Social Work increase, mainly due to the suppression of rights and the process of pauperization in the context of the accelerated advances in reactionarism and conservatism in Brazil. Both old and new challenges restate the relevance of the professional ethical and political project.
\end{abstract}

Keywords: Crisis of capital. Barbarism. Social Work.

\section{Introdução}

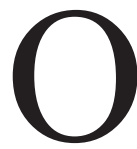

Serviço Social se constituiu historicamente e se realiza de maneira cotidiana como requisição do movimento da realidade, ou seja, a possibilidade histórica da profissão está relacionada ao movimento da totalidade concreta, ao desenvolvimento do modo de produção capitalista,

* Texto elaborado a partir da conferência realizada no Seminário Anual da Cortez Editora, em comemoração aos oitenta anos do Serviço Social, no dia 16 de maio de 2016, no Teatro Tuca na PUC-SP. Alguns extratos do texto constam em outras publicações da autora, indicadas ao longo do artigo. 
generalizando-se na passagem do capitalismo de livre concorrência para o capitalismo monopolista (Behring e Boschetti, 2016). Portanto, os oitenta anos do Serviço Social brasileiro se forjam na sua relação histórica com o enfrentamento às expressões da questão social, seja por meio das políticas sociais e materialização de direitos, seja na articulação com movimentos sociais da classe trabalhadora em sua luta pela conquista de direitos e de melhores condições de vida. Significa dizer que não se pode entender a história do Serviço Social de forma endógena, a partir de si mesma.

Sendo indissociável do processo de desenvolvimento da sociabilidade capitalista, não podemos negligenciar os processos que determinam sua possibilidade histórica: 1) a condição geral do trabalho assalariado, subsumido ao capital, que para se valorizar precisa extrair mais-valor, já que este é a base para o processo de acumulação; 2) a pauperização da classe trabalhadora e daqueles que não se inserem no assalariamento e conformam um exército de reserva ou superpopulação relativa; 3 ) as lutas sociais da classe trabalhadora que colocam na cena pública a questão social em suas mais diversas expressões.

Os desafios postos hoje ao Serviço Social reeditam "velhas" e históricas situações e colocam na agenda novos desafios diante da barbarização da vida em contexto de crise do capital e em contexto de particularização do avanço acelerado do reacionarismo e do conservadorismo no Brasil.

\section{Algumas expressões da barbárie contemporânea}

Em contexto de crise estrutural do capital, nos termos marxianos assumidos nesta análise (Marx, 2009; Mandel, 1990; Boschetti, 2016a) agudizam-se as expressões da questão social revelando a barbárie cotidiana que assola sem trégua a classe trabalhadora. Os processos contemporâneos de acumulação capitalista, em sua sanha para ampliar as taxas de lucros, se renovam incessantemente na tentativa de assegurar as bases sociais de reprodução do capital (Fontes, 2010). O embrutecimento das condições de vida e a destruição de direitos conquistados revelam os processos de expropriação ${ }^{1}$ ao qual a classe

1. Sobre o tema das expropriações, ver Marx (1984), Fontes (2010) e Boschetti (2016a). 
trabalhadora vem sendo subjugada e apontam os árduos desafios postos ao trabalho de assistentes sociais, que lidam cotidianamente com as mais variadas e agudas manifestações da questão social. Algumas dessas manifestações ${ }^{2}$ serão aqui problematizadas, sem nenhuma pretensão de esgotá-las.

\section{A barbárie dos deslocamentos forçados}

Talvez o mais bárbaro processo de expropriação contemporânea seja aquele que submete milhares de pessoas à condição de refugiados, ${ }^{3}$ arrancados de suas vidas, suas histórias, suas raízes, devido à violência, guerra civil, conflitos, pobreza ou desastres naturais, processo registrado pela sensível lente do fotógrafo Sebastião Salgado no livro Exxodos, na década de 1990. Essa "humanidade em trânsito" é a expressão de uma humanidade que tudo perdeu e a quem tudo foi roubado: perambulam pelo mundo buscando um lugar: fogem da guerra, são perseguidos políticos, foram expropriados de seus tetos, terras, empregos, em escala mundial sem precedentes. De acordo com a agência da ONU para refugiados (Acnur), ${ }^{4}$ os anos de 2014 e 2015 testemunharam o dramático aumento de deslocamento forçado em todo o mundo: em 2013 eram 51,2 milhões de pessoas, o número mais alto desde a Segunda Guerra Mundial; em 2014 já eram 59,5 milhões de pessoas, e ao final de 2015 eram 65,3 milhões de pessoas deslocadas em virtude de guerras e conflitos. Isso representa um aumento de $21,59 \%$ de deslocamentos forçados entre 2013 e 2015. A mesma agência informa que do total de 65,3 milhões, 12,4 milhões são novos deslocados

2. As formas de expropriação indicadas na sequência foram apresentadas no $5^{\circ}$ Encontro Nacional Serviço Social e Seguridade Social, organizado pelo CFESS, em Belo Horizonte (MG), em 20/11/2015.

3. Segundo a Convenção de 1951 relativa ao Estatuto dos Refugiados, "são refugiados as pessoas que se encontram fora do seu país por causa de fundado temor de perseguição por motivos de raça, religião, nacionalidade, opinião política ou participação em grupos sociais e que não possam (ou não queiram) voltar para casa. Posteriormente, definições mais amplas passaram a considerar como refugiados as pessoas obrigadas a deixar seu país devido a conflitos armados, violência generalizada e violação massiva dos direitos humanos". Cf. Definição da Agência para Refugiados da ONU (Acnur). Disponível em: < http://www.acnur. org/t3/index.php?id=252>. Acesso em: 17 nov. 2015 e 26 set. 2016.

4. Dados disponíveis em: <http://www.acnur.org/portugues/recursos/estatisticas/>. Acesso em: 26 set. 2016 . 
por conflitos e perseguições apenas em 2015. Informa ainda que o "universo de 65,3 milhões inclui 21,3 milhões de refugiados ao redor do mundo, 3,2 milhões de solicitantes de refúgio e 40,8 milhões deslocados que continuam dentro de seus países". As nações que mais originam os deslocamentos forçados para outras nações são a Síria (com 4,9 milhões de refugiados), o Afeganistão (com 2,7 milhões) e a Somália (com 1,1 milhão). Os países com maior número de deslocados internos são a Colômbia (6,9 milhões), a Síria (6,6 milhões) e o Iraque (4,4 milhões).

Seja em função dos deslocamentos externos ou internos, as condições das famílias que são obrigadas a abandonar suas casas e familiares se encontram expropriadas das mínimas condições de sobrevivência. São pessoas, famílias, jovens, crianças que tudo perderam, que buscam um lugar no mundo, que buscam simplesmente viver, e que são recusados violentamente, ou vivem em acampamentos absolutamente sub-humanos. A xenofobia, a intolerância e o nacionalismo fecham fronteiras, desumanizam, alimentam o ódio e a perda de sentido do humano genérico.

Não se trata de uma questão distante ou ausente da nossa realidade. Também segundo a Acnur, no Brasil o número de refugiados dobrou desde 2011, passando de 4.218 para 8.400 até agosto de 2015, e envolvem 81 nacionalidades diferentes: sírios, angolanos, colombianos, congoleses e libaneses. Não se tem dados disponíveis exatos, mas os jornais noticiaram que aproximadamente 160 famílias ou quatrocentos imigrantes refugiados recebem Bolsa Família. ${ }^{5}$ Essa condição coloca os refugiados em situação de pauperismo, que constitui o "mais profundo sedimento da superpopulação relativa [...]. O pauperismo é a camada social mais aviltada e "constitui o asilo para inválidos do exército ativo de trabalhadores e o peso morto do exército industrial de reserva" (Marx, 1984, p. 208). Os assistentes sociais são chamados a intervir no âmbito da gestão desse bárbaro processo de expropriação das condições mínimas de vida. Constitui, portanto, um imenso desafio debater como essa "expressão" dramática da questão social está sendo abordada no âmbito da política de assistência social.

5. Conforme dados divulgados pela agência BBC Brasil em 14/10/2015. Disponível em: <http://www. bbc.com/portuguese/noticias/2015/10/151013_bolsa_familia_sirios_lab $>$. Acesso em: 17 nov. 2015. 
Como as(os) assistentes sociais se posicionam diante dessa tragédia mundial? Que posicionamentos éticos orientam suas ações? ${ }^{6}$

\section{A barbárie da intolerância e do fundamentalismo religioso}

Não se pode e nem se deve relacionar diretamente o aumento dos processos migratórios ao aumento do fundamentalismo religioso, mas é inegável que os ataques/atentados terroristas reivindicados pelo Estado islâmico em diversos países (Egito, Líbano, Kwait, Tunísia, Turquia, Quênia, França) e suas bárbaras demonstrações de força, com marchas machistas, assassinatos de opositores, leilão de jovens meninas e o terror do medo provocaram grandes deslocamentos de famílias inteiras ou destroçadas nos conflitos em direção à Europa. Os recentes atentados na Europa, em especial na França, nos mostram, por um lado, a motivação do terrorismo covarde no Ocidente, que reivindica o atentado como retaliação ao imperialismo americano e europeu no Oriente Médio, em especial no Iraque e na Síria. Por outro lado, revela o caráter absurdamente conservador, no sentido do conservadorismo expresso por Mauro Iasi, como "uma expressão da luta de classes, isto é, que manifesta em sua aparência a dinâmica de luta entre interesses antagônicos que formam a sociabilidade burguesa". ${ }^{7}$

Ao provocar sucessivos ataques na Europa, o Estado islâmico não só revela sua disputa pela riqueza e poder dos territórios ocupados em diversos países do Oriente Médio, mas justifica sua violência em nome da religião. Com uma interpretação equivocada da religião islâmica, reivindica seu ataque a Paris, por ser a "capital do vício e da perversão". Na verdade, revela o profundo sentido do Estado islâmico de supressão de todas as formas de liberdade pela violência injustificável que tenta impor o poder pelo medo.

6. Antenado com essa questão, o Conselho Federal de Serviço Social organizou entre 6 e 8 de julho de 2016 o seminário nacional "Serviço Social, relações fronteiriças e fluxos migratórios internacionais". Disponível em: <http://www.seminariofronteiras.com.br/>. Acesso em: 28 set. 2016.

7. Conforme artigo "De onde vem o conservadorismo", publicado no blog da Boitempo em 15/4/2015. Disponível em: <https://blogdaboitempo.com.br/tag/12-de-abril/>. Acesso em: 17 nov. 2015. 
Mas o aumento da intolerância e do conservadorismo ${ }^{8}$ não se expressa somente no fundamentalismo islâmico, embora este possa ser sua expressão mais dogmática e violenta. $\mathrm{O}$ conservadorismo vem atraindo uma imensidão de jovens sem projetos coletivos de futuro em todo o mundo. No Brasil, se expressa cotidianamente, embora apenas algumas situações cheguem à grande mídia: o assassinato com fogo do líder indígena Galdino em Brasília (1997), o casal de moradores de rua queimados no Rio de Janeiro (2015), o adolescente agredido e preso a um poste no Rio de Janeiro (2014), as violências cotidianas contra gays, travestis e transexuais (604 assassinados entre 2008 e 2015, segundo a Transgender Europe), para quem o Brasil é o país que mais mata travestis e transexuais em todo o mundo. ${ }^{9}$ O Projeto de Lei (PL) n. 3.722/2012, aprovado na Comissão Especial da Câmara dos Deputados e que altera o Estatuto do Desarmamento (2003), de natureza conservadora, na prática libera a compra e o porte de arma no Brasil, o que tende a aumentar ainda mais essa violência cotidiana e muitas vezes invisível na mídia.

Estes não são somente dados empíricos sobre a violência cotidiana. São situações, ou expressões da questão social, com as quais se deparam cotidianamente os profissionais que atuam nas políticas sociais e são demandados a intervir nas situações de violência.

\section{A supressão e o antagonismo aos direitos humanos}

Além da violência cotidiana, a barbárie assume também a forma "democrática" de supressão e/ou questionamento dos direitos por meio de projetos de lei em tramitação no Poder Legislativo brasileiro. As proposições de redução da maioridade penal, do estatuto da família, as críticas à Lei Maria da Penha e a não criminalização da homofobia são expressões de supressão de direitos ou

8. Especificamente sobre o (neo)conservadorismo, consultar a revista Serviço Social \& Sociedade n. 124, de outubro de 2015, que se dedicou ao tema. Disponível em: $<$ http://www.scielo.br/scielo.php?script=sci issuetoc\&pid=0101-662820150004\&lng=pt\&nrm=is $>$. Acesso em: 27 set. 2016.

9. Conforme matéria na Agência EBC Brasil. Disponível em: $<$ http://agenciabrasil.ebc.com.br/direitos-humanos/noticia/2015-11/com-600-mortes-em-seis-anos-brasil-e-o-que-mais-mata-travestis-e >. Acesso em: 17 nov. 2015. 
de não aprovação de direitos de proteção às vítimas de violência e de criminalização da violência contra a mulher, contra os jovens e contra a população LGBT, todos fundamentados na intolerância religiosa. Como disse José Saramago: "Por causa e em nome de Deus é que se tem permitido e justificado tudo, principalmente o mais horrendo e cruel". ${ }^{10}$

A supressão dos direitos e a crescente predominância de posicionamentos conservadores contra os direitos humanos atingem de forma direta o trabalho de assistentes sociais, cujo desafio cotidiano é, justamente, buscar alternativas para ampliar o acesso aos direitos, lutar contra a destruição dos direitos conquistados, bem como pela sua ampliação. Assistentes sociais vêm sendo cada vez mais solicitados a intervir em situações de atendimento a mulheres que sofreram violência doméstica ou abuso sexual, atendimento a gays, lésbicas, travestis e transexuais em busca de garantia de seus direitos. O nosso Código de Ética interdita qualquer atitude discriminatória, mas alguns estudos vêm mostrando, de forma ainda pontual, que predominam muitas posturas intolerantes. São situações que exigem posicionamentos éticos desprovidos de qualquer orientação religiosa, o que nos coloca o imenso desafio de rever práticas conservadoras no âmbito das políticas sociais.

Ao lado dessas barbáries contra a humanidade e contra os direitos humanos, somam-se os processos de expropriação provocados pela exploração e destruição da natureza e dos direitos dos povos indígenas e quilombolas.

Violência e expropriação das terras indígenas e quilombolas

A expropriação violenta de terras indígenas e quilombolas é outra bárbara expressão da questão social. Além de fomentar a violência no campo, também destrói a cultura indígena e quilombola e os submetem às mais indignantes formas de sobrevivência. De acordo com o MDS, em torno de 112 mil famílias indígenas e 106 mil famílias quilombolas tinham nos benefícios do programa

10. Conforme artigo intitulado "O fator Deus", publicado na Folha on-line em 19/9/2001. Disponível em: <http://www1.folha.uol.com.br/folha/mundo/ult94u29519.shtml>. Acesso em: 17 nov. 2015. 
Bolsa Família sua única forma de sobrevivência e enfrentamento à condição de extrema pobreza. Mas sabe-se que isso não resolve a questão indígena e quilombola, que requer a demarcação das terras, impedida pelos lobbies do agronegócio. A PEC n. 215/2000, desarquivada pelo então deputado do PMDB Eduardo Cunha, afastado por corrupção, em aliança com a bancada BBB (Boi, Bala e Bíblia) foi aprovada em 27/10/2015 em comissão especial e regulamenta a demarcação de terras indígenas com esmero capitalista. A PEC é uma ameaça aos povos indígenas e quilombolas e às unidades de conservação, pois concede extremados poderes ao Legislativo para dar a palavra final nas demarcações e anulação de terras indígenas e quilombolas já demarcadas. A PEC, se aprovada definitivamente pelo Congresso brasileiro, contribuirá para dizimar a resistência indígena e quilombola e constitui mais uma expressão do avanço da barbárie.

\section{Precarização do trabalho e destruição dos direitos}

A restauração capitalista, na busca de ampliação das taxas de lucro, impõe a destruição de direitos do trabalho, da previdência, da saúde, que constituem uma "nova - e fundamental - forma de exasperação da disponibilidade dos trabalhadores para o mercado, impondo novas condições e abrindo novos setores para extração de mais valor" (Fontes, 2010, p. 54). Na perspectiva defendida pela autora, as expropriações por meio da subtração de direitos designam os processos econômicos e sociais que intensificam a disponibilização do trabalhador para o mercado e, ainda, criam novas formas de acumulação e extração de mais valor, a exemplo da mercantilização que se processa em campos anteriormente instituídos, como de prestação de serviços e bens públicos (trabalho, previdência, saúde, educação).

A expropriação, portanto, constitui um processo de subtração de condições históricas de reprodução da força de trabalho, por meio da reapropriação, pelo capital, de parte do fundo público destinado aos direitos conquistados pela classe trabalhadora. As recentes contrarreformas implementadas no âmbito do trabalho, com as alterações no seguro-desemprego e abono salarial pela MP n. 665/2014 (convertida na Lei n. 13.134, de 16/6/2015) e no âmbito da previdência com as restrições impostas à pensão por morte e auxílio doença pela MP n. 664/2015 
(convertida na Lei n. 13.135, de 17/6/2015), além das mudanças no fator previdenciário, com ampliação da idade para usufruto da aposentadoria (Lei n. 13.135, de 17/6/2015), são exemplares nesse processo de expropriação contemporâneo.

Além de relações precarizadas e sem direitos que atingem mais da metade da população economicamente ativa, o PL n. 4.330/2004 — conhecido como PL da Terceirização, já aprovado na Câmara dos Deputados, e desde abril de 2015 aguardando sua análise no Senado - constitui mais um ataque aos direitos da classe trabalhadora. O projeto de lei possibilita ampliar a precarização para atividades essenciais, como saúde e educação. Outras medidas seguem no mesmo sentido, como a transformação dos hospitais universitários em empresas brasileiras de serviços hospitalares, ou a aprovação, no dia 21 de outubro de 2016, da Proposta de Emenda à Constituição (PEC) n. 395/2014, que permite às universidades cobrar por cursos de pós-graduação lato sensu (especialização), de extensão e de mestrado profissional.

Esses bárbaros ataques aos direitos sociais e trabalhistas serão ainda mais agudizados se for aprovada a PEC n. 241/2016, apresentada pelo presidente Temer em junho de 2016, que impõe congelamento por vinte anos dos gastos da União e limita as despesas ao equivalente aplicado no ano anterior, corrigidos apenas pela inflação. Vários estudos já vêm mostrando o impacto que essa medida terá nas próximas décadas na redução de recursos para as políticas sociais.

Estamos, portanto, num período de contraofensiva capitalista às conquistas civilizatórias resultantes das lutas sociais, um ambiente extremamente destrutivo dos direitos sociais, de aniquilamento dos direitos humanos, de destruição da natureza, de criminalização dos movimentos sociais e de avanço acelerado do conservadorismo. O capital está destruindo a humanidade e agudizando os processos de pauperização, o que exige renovados desafios e contundentes respostas por parte da classe trabalhadora.

\section{Tensões e desafios contemporâneos}

Nesses tempos de agudização da barbárie, o Projeto Ético-Político do Serviço Social brasileiro, construído coletivamente nos últimos quarenta anos, 
surge como renovada semente de esperança na luta contra todas as formas de exploração e opressão que intensificam a barbárie. Ancorado nos princípios da liberdade, equidade, compromisso com as lutas da classe trabalhadora, socialização da riqueza, recusa a todas as formas de discriminação e defesa intransigente dos direitos sociais, constitui uma bússola para enfrentar os desafios que a realidade impõe.

Nesses oitenta anos de profissão, ${ }^{11}$ a intervenção profissional se consolidou predominantemente no campo das políticas sociais, ${ }^{12}$ balizada pela perspectiva de materialização de direitos sociais, como saúde, educação, previdência social, assistência social, moradia, lazer, trabalho. São diferentes e variadas competências e atribuições profissionais realizadas no dia a dia, ${ }^{13} \mathrm{em}$ sua maioria na relação direta com os(as) trabalhadores(as) em condições de violação de direitos, que buscam no Serviço Social uma possibilidade para aceder à informação e à orientação para acesso aos bens e serviços públicos.

Embora o campo das políticas sociais seja por excelência o espaço da intervenção profissional, nunca é demais afirmar que o Serviço Social não se confunde com nenhuma política social e não se vincula exclusivamente a nenhuma delas, mas se institui e se consubstancia materialmente no processo teórico-político de condução das políticas sociais. Nas últimas três décadas, a perspectiva designada por Netto (1991 e 2011) de "intenção de ruptura" firmou o Serviço Social como fundamental campo de reflexão, formulação e teorização crítica sobre a política social na sociabilidade capitalista. Nessa mesma direção,

11. Parte desse item foi publicado no texto "Serviço Social e política social: 80 anos de uma relação visceral", escrito com Elaine Behring e publicado no livro Serviço Social no Brasil. História de resistências e de ruptura com o conservadorismo.

12. Não se tem dados exatos sobre a distribuição profissional nas diferentes áreas de atuação. Segundo o CFESS, ao final de 2015 havia aproximadamente 160 mil assistentes sociais inscritas(os) nos Cress. Desse total, calcula-se que $90 \%$ atuam nas políticas sociais nos três níveis da federação. O Censo Suas 2014 indica que atuam na política de assistência social um total de 42.669 profissionais (rede pública e privada), o que corresponde a $27 \%$ do total. Os demais se distribuem entre as outras políticas sociais, como saúde, previdência social, educação, habitação, espaço sociojurídico e outros espaços de intervenção.

13. Estabelecidas legalmente na Lei de Regulamentação Profissional, Lei n. 8.662, de 7 de junho de 1993. Disponível em: <http://www.planalto.gov.br/ccivil_03/leis/L8662.htm>. Consultar também outras infrarregulamentações disponíveis na página do CFESS: <http://www.cfess.org.br/visualizar/menu/local/ regulamentacao-da-profissao>. Acesso em: 28 jan. 2016. 
nas palavras de Mota (2016, p. 166), "o Serviço Social, ao fim e ao cabo dos seus 80 anos de existência no Brasil, vem robustecendo seu protagonismo intelectual e político na formação de uma cultura (teórico-metodológica, ideológica e política) que se contrapõe à hegemonia dominante, em articulação com a esquerda marxista em nosso país".

Nisso se distancia não somente de sua origem nacional, mas também do exercício da profissão em grande parte do mundo, ainda subjugado a práticas convencionais e/ou conservadoras, orientadas pela perspectiva sistêmica funcional ao capital.

Romper hegemonicamente com o conservadorismo e situar-se na mediação entre as necessidades sociais e a realização de direitos na sociabilidade capitalista obriga o Serviço Social a conviver de forma constante com tensões próprias das relações sociais capitalistas, inscritas no imperativo de permanente produção e reprodução do capital, ou, como afirma Marx: "O limite da produção é o lucro dos capitalistas e jamais as necessidades dos produtores” (2009, p. 151). A contradição perene entre as demandas e lutas por direitos da classe trabalhadora e os ditames da acumulação do capital, que requer a mercantilização de bens e serviços, coloca a profissão no "fio da navalha" dos antagonismos de classe e lhe atribui imenso desafio cotidiano.

Colocar-se eticamente em defesa dos direitos da classe trabalhadora é uma postura ético-política e teórica essencial para assegurar a emancipação política, mas não assegura a igualdade substantiva e nem garante a satisfação das necessidades da classe trabalhadora. Essa tensão estrutural se agudiza em tempos de crise, de avanço do conservadorismo, de criminalização das lutas sociais, de destruição e retenção de direitos sociais, e impõe novos e também antigos desafios aos profissionais.

Essa estrutural e histórica tensão impele os assistentes sociais a reconhecer e assumir que, contraditoriamente, o Estado social, ao conjugar direitos resultantes da luta de classes, possibilitou o alcance da emancipação política, mas não assegura a emancipação humana (Boschetti, 2016a). Se, por um lado, a cidadania possível e concretizada no âmbito do Estado social capitalista pode "perturbar" a lei geral da acumulação capitalista, ao tencionar o capital, por outro, contraditoriamente, participa da reprodução ampliada do capital, sendo 
a este cada vez mais subordinada, sobretudo em tempos de agudização das crises do capital.

Lutar, defender e materializar direitos no exercício da profissão, portanto, caracteriza-se como um desafio cada vez mais requerido no confronto capital/ trabalho, mas pressupõe situar o sentido e a dimensão dos direitos e das políticas sociais que os materializam num projeto coletivo mais amplo de supressão da sociabilidade mercantilizada.

Em contexto de crise, as políticas sociais são os principais alvos da mercantilização, da focalização, da privatização, da transformação de bens e serviços em mercadorias destinadas a manter aquecido o consumo e a competitividade, e sofrem diretamente a ofensiva capitalista em sua permanente busca por superlucros.

Em sua peleja para assegurar direitos e universalizar as políticas sociais, os(as) assistentes sociais são duramente tencionados com exigências institucionais para endurecer critérios de elegibilidade, estabelecer ou ampliar condicionalidades e contrapartidas, focalizar benefícios e prestações assistenciais e previdenciárias, reduzir o nível dos benefícios sociais, desenvolver serviços sem as devidas condições financeiras e institucionais, transferir cuidados e proteção públicos às famílias e/ou organizações não governamentais, entre outras demandas que impõem intransponíveis limites à universalização das políticas e dos direitos.

O trabalho profissional esbarra cotidianamente nesses limites e desafia o(a) assistente social a situá-los na totalidade histórica, como condição para não cair no voluntarismo e pragmatismo tão presentes nos primórdios da profissão, e como estratégia interventiva fundamental para a socialização de informações e a construção de processos educativos junto aos usuários com quem trabalha. Por isso, multiplicam-se os desafios contemporâneos, alguns aqui sinalizados:

a) Compreender e traduzir as implicações da crise para os direitos, as políticas sociais e para as condições de vida da classe trabalhadora

Cabe ao profissional entender e desmistificar as interpretações superficiais e equivocadas da crise, que a restringem aos seus efeitos e não reconhece suas 
causas, enraizadas no antagonismo entre produção social e apropriação privada da riqueza, ou, como afirma Marx (2009, p. 85), "as crises são manifestações das contradições inerentes ao modo de produção capitalista".

Traduzir no âmbito profissional o significado estrutural da crise do capital possibilita desmistificar diversos mitos que encobrem a persistência da desigualdade e da pobreza, o aumento do desemprego e de relações informais de trabalho sem direitos, a falta de qualidade na saúde pública, a redução da previdência pública, a expansão do ensino privado em todos os níveis, as crescentes expressões de violência no campo e na cidade e contra a juventude negra.

Possibilita entender que parte significativa do fundo público é desviado do orçamento que deveria ser aplicado nas políticas sociais e transferido para o pagamento de juros da dívida pública, o que favorece e alimenta imensamente o capitalismo financeirizado (Salvador, 2010; Behring, 2012; Fontes, 2010) e restringe recursos para os direitos.

Possibilita compreender que a disputa de classes pelo fundo público favorece sempre o empresariado e os mais elevados salários, já que a carga tributária é altamente regressiva e onera intensamente a classe trabalhadora e os baixos salários (Salvador, 2010). Possibilita entender que a política econômica de juros altos impõe elevado custo de vida, com aumento de preços, aumento de tarifas públicas e perdas salariais.

Desmistificar essa conjuntura é essencial para deslindar a condição contemporânea do trabalho e da política social e entender as determinações sócio-históricas de conformação do trabalho profissional e das condições de realização do Projeto Ético-Político profissional.

b) Compreender e traduzir a condição e o significado dos direitos e das políticas sociais e suas implicações para 0 trabalho profissional

Trata-se de enorme desafio decifrar e demonstrar que no Brasil as políticas sociais estão longe de alcançar a universalidade e de reduzir a desigualdade estrutural provocada pela concentração de renda e propriedade, embora sejam as únicas alternativas da classe trabalhadora para acessar a educação, a saúde, 
o transporte subsidiado e os benefícios que asseguram certo rendimento na ausência do trabalho (previdência, assistência social, seguro-desemprego).

Significa dizer que, por mais que os(as) profissionais se dediquem incansavelmente ao exercício de suas atribuições e competências, o resultado de seu trabalho estará sempre determinado, por um lado, pela própria condição da política social, e por outro, pela sua condição de trabalhador inserido na divisão sociotécnica do trabalho.

Como trabalhador(a), o(a) assistente social vivencia a mesma injunção de relações precarizadas e baixos salários que atinge a maioria da classe trabalhadora. ${ }^{14}$ Seu cotidiano de trabalho é caracterizado por uma imensa desigualdade e disparidade salarial, ${ }^{15}$ tanto entre esferas de governo (federal, estadual e municipal), quanto entre os poderes (Legislativo, Judiciário e Executivo) e as políticas sociais. Essa disparidade é marcada pelos baixos salários, o que obriga muitos profissionais a duplos ou triplos contratos de trabalho. Também enfrenta condições de trabalho insatisfatórias que não atendem ao disposto na Resolução CFESS n. 493/2006, ${ }^{16}$ como inexistência de espaço físico exclusivo para atendimento sigiloso, ausência de equipamentos para guarda de material ou para realização do trabalho, a exemplo de carros para visitas domiciliares, computadores com internet, material específico e especializado.

A intensificação das rotinas de trabalho é uma realidade em praticamente todas as áreas de atuação, em decorrência do aumento das demandas e incompatibilidade com o quadro de profissionais concursados ou contratados.

Os(as) assistentes sociais enfrentam, ainda, o desconhecimento por parte da instituição ou de outros profissionais de suas competências e atribuições;

14. Os parágrafos seguintes foram desenvolvidos por Boschetti no texto "Crise do capital, (des)construção da seguridade social e a particularidade da assistência social no Brasil", apresentado em palestra proferida no $6^{\circ}$ Seminário Nacional Estado e Política Social e no $2^{\circ}$ Seminário de Direitos Humanos Unioeste, setembro 2014 e publicado posteriormente no livro Direitos e política social (2016b).

15. Não se dispõe de dados nacionais detalhados, mas breve pesquisa em editais de concursos abertos e disponíveis publicamente em janeiro de 2016 revelam salários variando entre 2,2 salários mínimos em prefeituras do interior a 12,8 salários mínimos em Tribunais de Justiça. Acesso a vários editais em 20 jan. 2016.

16. A Resolução CFESS n. 493/2006 estabelece as condições éticas e técnicas para o exercício do trabalho. Disponível em: <http://www.cfess.org.br/arquivos/Resolucao_493-06.pdf >. Acesso em: 28 jan. 2016. 
vivenciam situações de desvalorização ou desqualificação profissional, o que provoca demandas de trabalho estranhas às suas competências e atribuições. A desregulamentação dos direitos, o endurecimento dos processos de trabalho e a fragmentação das tarefas levam a um processo de diluição das particularidades e especificidades profissionais. Desta forma, muitas vezes o(a) assistente social é chamado(a) a fazer tudo e qualquer coisa, o que implica nítido desrespeito à sua formação e titulação.

Nesse contexto barbaramente regressivo, emergem traços renovados de conservadorismo que atingem a formação e o trabalho profissional, como o metodologismo, o teoricismo acrítico, o aligeiramento da formação e da pesquisa, o pragmatismo, o voluntarismo e o voluntariado, o contentamento com o possibilismo, que reeditam características do passado recente (Boschetti, 2015). São incidências conservadoras que remodelam a atuação do Serviço Social nas políticas sociais e podem fazer retroceder as históricas conquistas alcançadas nos últimos três decênios e que marcaram a ruptura com o Serviço Social acrítico.

Temos hoje o imenso desafio de incorporar e consolidar cotidianamente os princípios ético-políticos construídos nas últimas quatro décadas, que nos possibilitaram alçar a profissão de seu lugar de origem, de reprodução do pensamento conservador, para o lugar que ocupamos atualmente, de espaço de resistência ao pensamento conservador. Esses valores e princípios precisam ser constantemente traduzidos e concretizados por meio de mediações que se realizam cotidianamente nos espaços de intervenção profissional na reafirmação de direitos que, sabemos, não podem se esgotar na cidadania burguesa.

\section{Considerações finais}

Para finalizar, considero que a relação e o vínculo entre os princípios e valores do nosso Projeto Ético-Político profissional e as ações necessárias para sua consolidação cotidiana requerem a desmistificação dos direitos e da cidadania burguesa e a real compreensão das suas dimensões e significado na sociabilidade capitalista; a firme disposição política, teórica e ideológica para 
assumir e participar das lutas da classe trabalhadora e para se colocar contra todas as formas de supressão de direitos e contra todas as formas de exploração econômica e opressão de gênero, geração, etnia, orientação sexual; a identificação das condições objetivas e subjetivas determinantes das relações sociais em cada contexto histórico e a capacidade de explorar suas contradições com vistas a defender, intransigentemente, os direitos da classe trabalhadora.

A barbárie capitalista contra a humanidade e a solidariedade de classe exige de todos nós a firme convicção de que somente a emancipação humana da sociedade de mercado será capaz de impor fim à sua existência.

Recebido em 30/9/2016 - Aprovado em 13/10/2016

\section{Referências bibliográficas}

AGÊNCIA EBC BRASIL. Disponível em: <http://agenciabrasil.ebc.com.br/direitos-humanos/noticia/2015-11/com-600-mortes-em-seis-anos-brasil-e-o-que-mais-mata-travestis-e>. Acesso em: 17 nov. 2015.

ACNUR (Agência para Refugiados da ONU). Disponível em: <http://www.acnur.org/ t3/index.php?id=252>. Acesso em: 17 nov. 2015 e 26 set. 2016.

BBC Brasil. Disponível em: <http://www.bbc.com/portuguese/noticias/2015/10/151013 bolsa_familia_sirios_lab>. Acesso em: 17 nov. 2015.

BEHRING, Elaine. Rotação do capital e crise: fundamentos para compreender o fundo público e a política social. In: SALVADOR, Evilásio et al. (Org.). Financeirização, fundo público e política social. São Paulo: Cortez, 2012.

; BOSCHETTI, Ivanete. Serviço Social e política social: 80 anos de uma relação visceral. In: SILVA, Maria Liduína Oliveira e (Org.). Serviço Social no Brasil: história de resistências e de ruptura com o conservadorismo. São Paulo: Cortez 2016.

BOSCHETTI, Ivanete. Assistência social e trabalho no capitalismo. São Paulo: Cortez, 2016a. 
BOSCHETTI, Ivanete. Crise do capital, (des)construção da seguridade social e a particularidade da assistência social no Brasil. In: RIZZOTO, M. L. F.; ROESLER, M. R. B.; MIRALES, R. (Orgs.). Direitos e politica social. Cascavel: Edunioeste, 2016b.

. Expressões do conservadorismo na formação profissional. Serviço Social \& Sociedade, São Paulo, n. 124, p. 637-651, dez. 2015. Disponível em: <http://www. scielo.br/scielo.php?script=sci_arttext\&pid=S0101-66282015000400637\&lng=pt\&nr $\mathrm{m}=\mathrm{is} \& \mathrm{t} \operatorname{lng}=\mathrm{pt}>$. Acesso em: 28 set. 2016.

CONSELHO FEDERAL DE SERVIÇO SOCIAL (CFESS). Resolução n. 493/2006. Estabelece as condições éticas e técnicas para o exercício do trabalho. Disponível em: $<$ http://www.cfess.org.br/arquivos/Resolucao_493-06.pdf>. Acesso em: 28 jan. 2016.

. Lei de Regulamentação Profissional, Lei n. 8.662, de 7 de junho de 1993. Disponível em: <http://www.planalto.gov.br/ccivil_03/leis/L8662.htm>. Acesso em: 27 set. 2016.

FONTES, Virgínia. O Brasil e o capital-imperialismo: teoria e história. Rio de Janeiro: Ed. da UFRJ, 2010.

IASI, Mauro. De onde vem o conservadorismo, publicado no blog da Boitempo em 15 abr. 2015. Disponível em: <https://blogdaboitempo.com.br/tag/12-de-abril/>. Acesso em: 17 nov. 2015.

MANDEL, E. A crise do capital. São Paulo: Ensaio/Ed. da Unicamp, 1990.

MARX, Karl. A assim chamada acumulação primitiva. In: . O capital. São Paulo: Ed. Victor Civita, 1984. v. 1, Livro I, t. 2. (Col. Os economistas.)

. Les crises du capitalisme. Preface de Daniel Bensaïd. [Text inédit]. Paris: Éditions Demopolis, 2009.

MOTA, Ana Elizabete. Serviço Social brasileiro: insurgência intelectual e legado político. In: SILVA, Maria Liduína de Oliveira e (Org.). Serviço Social no Brasil: história de resistências e de ruptura com o conservadorismo. São Paulo: Cortez, 2016.

NETTO, José Paulo. Ditadura e Serviço Social: uma análise do Serviço Social no Brasil pós-64. São Paulo: Cortez, 1991.

. As perspectivas teórico-metodológicas contemporâneas no Serviço Social. In: SESC/CBCISS (Org.). O trabalho social França-Brasil. São Paulo: Ed. Sesc/CBCISS, 2011 . 
SALVADOR, Evilásio. Fundo público e seguridade social no Brasil. São Paulo: Cortez, 2010.

SARAMAGO, José. "O fator Deus", publicado na Folha on-line em 19 set. 2001. Disponível em: <http://www1.folha.uol.com.br/folha/mundo/ult94u29519.shtml>. Acesso em: 17 nov. 2015.

SERVIÇO SOCIAL \& SOCIEDADE. São Paulo, n. 124, out./dez. 2015. 